Case Report

\title{
A rare case of intrahepatic gallbladder in the setting of penetrating liver injury, a retrospective diagnosis: a case report
}

\author{
V. Kopperundevi, Joyce Prabhakar*, Samarthan S. L., R. Kannan
}

Institute of General Surgery, Madras Medical College, RGGGH, Chennai, Tamil Nadu, India

Received: 14 January 2022

Revised: 01 February 2022

Accepted: 03 February 2022

\author{
*Correspondence: \\ Dr. Joyce Prabhakar, \\ E-mail: joycesurgeon@gmail.com
}

Copyright: (C) the author(s), publisher and licensee Medip Academy. This is an open-access article distributed under the terms of the Creative Commons Attribution Non-Commercial License, which permits unrestricted non-commercial use, distribution, and reproduction in any medium, provided the original work is properly cited.

\begin{abstract}
Intrahepatic gallbladder is a rare congenital variant among the ectopic gallbladder. Inadequate preoperative imaging studies might mislead the surgeon and most of the times can create unnecessary complications in the setting of cholecystectomy. Often these anomalies are either picked up intraoperatively or by retrospective diagnosis. Patients usually are at a high risk for developing cholelithiasis due to abnormality in the contractile ability of the gallbladder. The clinical symptoms can be misleading to many of the clinicians as recurrent dull aching right upper abdominal pain for many years, treated for acute peptic disease and dyspepsia.
\end{abstract}

Keywords: Intrahepatic gallbladder, Ectopic gallbladder, Liver injury, Magnetic resonance cholangio pancreaticography

\section{INTRODUCTION}

Ectopic gallbladder is a rare congenital variant of gallbladder, affected by a large number of congenital anomalies, which may affect its number, size, location or form. ${ }^{1}$ Some of these malformations are very rare like in this case report right sided intrahepatic gallbladder and may lead to misdiagnosis both clinically and radiologically. Given the frequency of the rarity of these anomalies and the widespread usage of ultrasonography examination for biliary tract diseases, radiologists should be aware of these conditions. The incidence of ectopic gallbladder can be 0.1 to $0.7 \%$ in total, with intrahepatic gallbladder as we present in this case is still rare being one of the types of ectopic gallbladder along with floating, retro spaced and absent gallbladder. In this case we did a retrospective diagnosis of the intrahepatic gallbladder from an incidental finding during the laparotomy of a 22-year-old female with grade 4 liver injury showing empty gallbladder fossa with normal extra hepatic biliary tree. The clinical significance of the ectopic gallbladder is emphasised because it may alter the clinical presentation of biliary tract diseases and pose technical difficulties during the surgery.

\section{CASE REPORT}

A 22-year-old female presented to the casualty with stab injury over the epigastrium, with associated multiple lacerations over the left side of her body.

On examination, the patient was pale, tachycardia and hypotension present. Per abdomen examination showed a stab injury with entry site of size $3 \times 2 \mathrm{~cm}$, on insinuating the little finger, the peritoneal breach could be made out with localised guarding over the epigastrium present, no diffuse guarding or rigidity, bowel sounds sluggish. Per rectal examination was normal.

eFAST was done bedside that showed gross free fluid in the peritoneum most probably hemoperitoneum due to solid organ injury in this case depending on the entry site mostly liver. Patient was transferred to the intensive care unit for resuscitation. Once hemodynamic stabilization 
was achieved the patient was taken for upfront exploratory laparotomy.

\section{Intraoperative}

Gross hemoperitoneum with grade 4 liver injury proceeded with thorough lavage and closure due to spontaneous thrombosis of the lacerated liver segment.

Incidentally gallbladder fossa was found to be empty with normal extra hepatic biliary tree.

This prompted the retrospective imaging of the hepatic biliary system on post operative day 10 with:

Ultrasound showing right sided segment 5 intrahepatic gallbladder (Figure $1 \mathrm{~A}$ ).

Magnetic resonance cholangio pancreaticography (MRCP) showing normal biliary tree with segment 5 intrahepatic gallbladder (Figure 1 B).

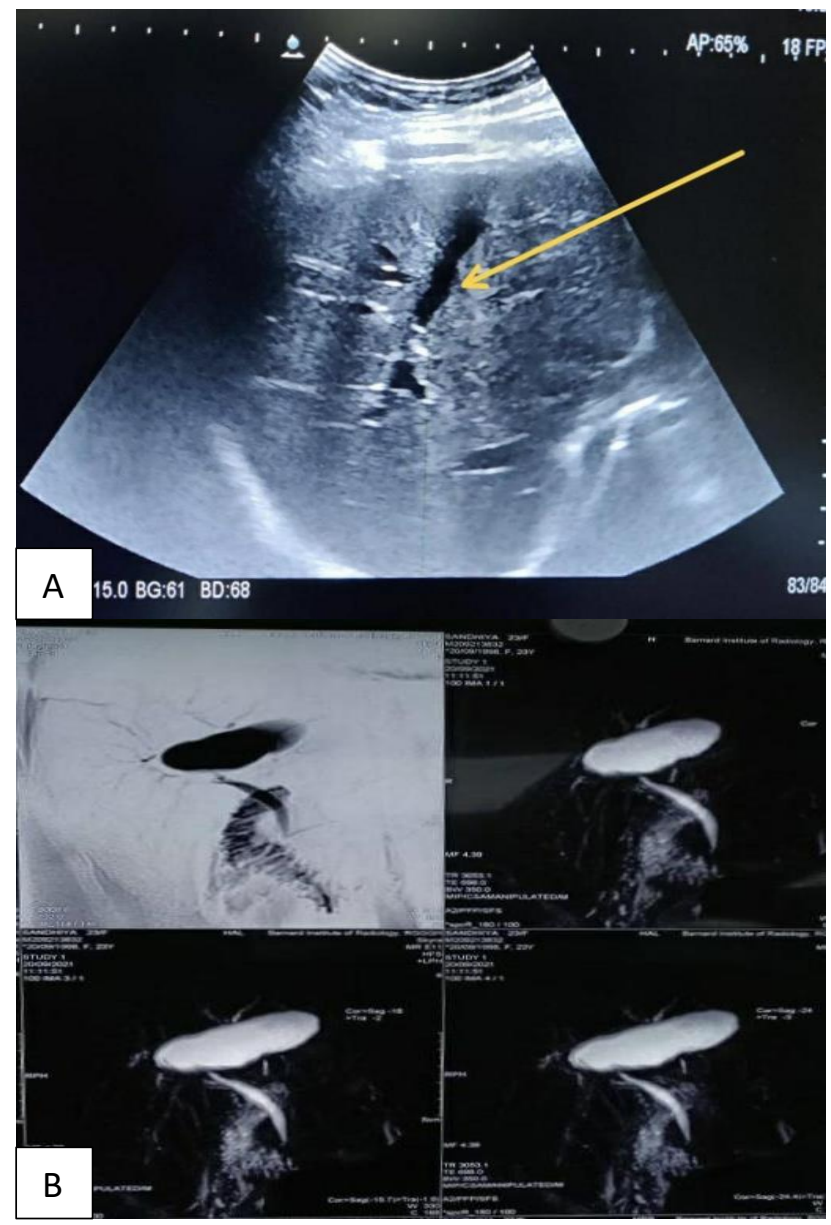

Figure 1 (A and B): Ultrasound of intrahepatic gallbladder (arrow mark) and MRCP of the normal segment 5 intrahepatic gallbladder.

Patient was discharged and kept on follow up. Since these patients are at a higher risk of developing cholelithiasis and cholecystitis at a younger age.

\section{DISCUSSION}

Rafailidis et al showed that, hepatobiliary-pancreatic system develops from the hepatic diverticulum from the ventral wall of the primitive midgut during the $4^{\text {th }}$ week of gestation and is composed of two buds, namely cranial bud and caudal bud. ${ }^{1}$ Cranial bud gives rise to the liver and the extrahepatic biliary system, whereas the caudal one divides into superior and inferior buds. The superior gives rise to the gallbladder and cystic duct, the latter gives rise to the ventral pancreas. By $5^{\text {th }}$ week the entire biliary system can be visualized but the gallbladder remains solid until $12^{\text {th }}$ week of gestation. Normally, the gallbladder lies within the gallbladder fossa underneath the liver in the plane of interlobular fissure. Its neck is found in the porta hepatis and extends to the caudal border of the liver. In $70 \%$ of cases, main lobar fissure is seen in longitudinal view in ultrasound as linear hyperechoic, lying between the gallbladder caudally and right portal vein cranially. On a transverse view gallbladder lies just posterior to the main lobar fissure and between the right hepatic lobe and the medial segment of the left lobe.

The four most common ectopic positions of the gallbladder are: Under the left liver lobe, inside the liver (as in our case)-intrahepatic gallbladder, transverse and retro placed and or floating gallbladder

Yadav et al showed that ectopic positions of the gallbladder can also be identified by CT angiography studying the position of the cystic artery. ${ }^{2}$ Less common positions include the falciform ligament, suprahepatic (usually between the right lobe of the liver and the diaphragm), the abdominal wall and behind the pancreas. The incidence varies from 0.1 to $0.7 \%$.

In our case, the gallbladder was found to be located in segment 5 of the right lobe of the liver as Intrahepatic gallbladder. This was later confirmed by MRCP. These positions are of great clinical significance as they alter the clinical presentation of cholelithiasis and cholecystitis, they create technical difficulties during biliary procedures. In particular, regarding the use of electrocautery in these conditions should be limited and no structure should be divided until a thorough inspection of the biliary tree is done. Thus, the radiologist must always inform the surgeon about the presence of an ectopic gallbladder. Preoperative imaging importance shown by Whittle et al includes ultrasonography, MRCP, Computed tomography and ERCP for diagnosis of ectopic gallbladder. ${ }^{3}$ Other anomalies include agenesis of gallbladder and duplication of the gallbladder. The former with an incidence of 0.007 to $0.13 \%$ and is usually associated with the congenital syndromes like KlippelFeil syndrome, trisomy 18 . Regarding the shape of the gallbladder, they can be Phrygian cap anomaly, a multi septate gallbladder, sometimes might be associated with choledochal cyst. Cholecystectomy with preoperative planning has to be done in cases of presence of right 
hypochondriac pain with evidence of cholecystitis. Lobo et al from their case series of cadaveric dissection of hepato biliary system inferred that the congenital anomalies of gallbladder is a rare entity. ${ }^{4}$ Monib et al concluded that awareness of ectopic gallbladder allows proper preoperative planning and will often require surgery at the earliest due to increased risk of cholelithiasis. ${ }^{5}$ Alkatout et al showed that the very rare entity of extra abdominal placed gallbladder in a neonate without the typical cholestasis symptoms. ${ }^{6}$ Schultz et al did a report on accurate diagnosis of intrahepatic gallbladder with the help of $99 \mathrm{mTc}$ sulfur colloid and 131I-rose bengal in a cirrhotic patient with suspected intrahepatic neoplasm. ${ }^{7}$ D'amato et al confirmed the presence of gallbladder near the hepatic dome by hepatobiliary scan in a suspected hepatic neoplasm. ${ }^{8}$ Wang et al studied the embryological reason for the ectopic gallbladder. ${ }^{9}$ Mathis et al showed the relationship between the congenital anomalies like omphalocele with the later presentation of ectopic pelvic gallbladder in a case report, adding to the various types of ectopic gallbladder. $^{10}$

\section{CONCLUSION}

This case report showing one of the rarest variants of ectopic gallbladder tells us that, we must keep in mind that ultrasonography is the primary imaging modality for gallbladder anomalies with CT, MRI being even more helpful, and the MRCP providing a thorough visualisation of the biliary tract. In our case, we presented a case of ectopic gallbladder as a result of incidental intraoperative finding confirmed by a retrospective imaging diagnosis.

Funding: No funding sources Conflict of interest: None declared

Ethical approval: Not required

\section{REFERENCES}

1. Rafailidis V, Varelas S, Kotsidis N, Rafailidis D. Two congenital anomalies in one: An ectopic gallbladder with Phrygian cap deformity. Case Rep Radiol. 2014;2014:246476.

2. Yadav A, Ray S, Nundy S. Ectopic gallbladder: A case report. SAGE Open Med Case Rep. 2021;9:2050313X211036777.

3. Whittle C, Skoknic V, Maldonado I, Schiappacasse G, Pose G. Multimodality Imaging of Congenital Variants in the Gallbladder: Pictorial Essay. 2012;30724869.

4. Lobo SW, Menezes RG, Mamata S, Baral P, Kanchan T, Hunnargi SA et al. Ectopic partial intrahepatic gallbladder with cholelithiasis--a rare anomaly. Nepal Med Coll J. 2007;9(4):286-8.

5. Monib S, Mahapatra P, Habashy HF. Intrahepatic Gallbladder. Eur J Case Rep Intern Med. 2019;6(6):001123

6. Alkatout I, Henopp T, Moritz JD, Nikischin W, Klöppel G, Engler S. Extraabdominal malposition of the gallbladder. J Pediatr Surg. 2008;43(11):e41-4.

7. Schulz RC, Shields JB, Fletcher JW, Donati RM. Liver scanning and the intrahepatic gallbladder: Case report. J Nuclear Med. 1975;16(11):1029-30.

8. D'amato DW, Balon HR, Arpan PJ. An "UpsideDown" Liver and Gallbladder Discovered on Hepatobiliary Scan. Clin Nucl Med. 1999;24(2):1402.

9. Wang BJ, Kim JB, Yu HC, Rodríguez-Vázquez JF, Murakami G, Cho BH. Fetal intrahepatic gallbladder and topographical anatomy of the liver hilar region and hepatocystic triangle. Endosc Ultrasound. 2018;7(3);PMC6032695.

10. Mathis R, Stodghill J, Shaver T, Younan G. Cholecystectomy of an Intrahepatic Gallbladder in an Ectopic Pelvic Liver: A Case Report and Review of the Literature. Caser Rep Surg. 2017;3568768.

Cite this article as: Kopperundevi V, Prabhakar J, Samarthan SL, Kannan R. A rare case of intrahepatic gallbladder in the setting of penetrating liver injury, a retrospective diagnosis: a case report. Int Surg J 2022;9:756-8. 